\title{
Intelligent Vision-based Navigation System for Mobile Robot: A Technological Review
}

\author{
Muhammad Hafidz Fazli Md Fauadi ${ }^{1}$, Suriati Akmal ${ }^{1}$, Mahasan Mat Ali ${ }^{1}$, Nurul Izah Anuar ${ }^{2}$, Samad \\ Ramlan $^{3}$, Ahamad Zaki Mohd Noor ${ }^{1}$, Nurfadzylah Awang ${ }^{1}$ \\ ${ }^{1}$ Fakulti Kejuruteraan Pembuatan, Universiti Teknikal Malaysia Melaka, Hang Tuah Jaya, 76100 Durian Tunggal, Melaka, Malaysia. \\ ${ }^{2}$ Faculty of Engineering and Technology, Multimedia University, 75450 Ayer Keroh, Melaka, Malaysia. \\ ${ }^{3}$ Silterra Malaysia Sdn Bhd, Kulim Hi-Tech Park, 09000, Kulim, Kedah, Malaysia.
}

\section{Article Info}

Article history:

Received Jul 23, 2018

Revised Sept 2, 2018

Accepted Oct 16, 2018

\section{Keyword:}

Mobile robot, Vision-based Navigation, Intelligent algorithm

SLAM

\begin{abstract}
Vision system is gradually becoming more important. As computing technology advances, it has been widely utilized in many industrial and service sectors. One of the critical applications for vision system is to navigate mobile robot safely. In order to do so, several technological elements are required. This article focuses on reviewing recent researches conducted on the intelligent vision-based navigation system for the mobile robot. These include the utilization of mobile robot in various sectors such as manufacturing, warehouse, agriculture, outdoor navigation and other service sectors. Multiple intelligent algorithms used in developing robot vision system were also reviewed.
\end{abstract}

\section{Corresponding Author:}

Muhammad Hafidz Fazli Md Fauadi

Fakulti Kejuruteraan Pembuatan,

Universiti Teknikal Malaysia Melaka,

76100 Durian Tunggal,

Melaka, Malaysia.

Email: hafidz@utem.edu.my

\section{Introduction}

The nature of operations for many industrial and service applications are changing due to the advancement of sciences and technologies. These include the applicability of various state-of-the-art methods [1-4] in contributing towards the advancement. The latest feasibility of Internet of Things [5] that propels Industrial Revolution 4.0 also has contributed towards establishing better applications. Among the most highly impacted applications is the mobile robot navigation system. Navigation is the fundamental concept for every robot to be mobile. There are two basic types of navigations [6]. The first one is local navigation that deals with the environmental situation within low range of distance in order to avoid obstacle or collision occurs. Another is categorized as global navigation refers to the localization of the robot on a larger scale environment using a global map or pre-specified topological maps regarding the robot's initial position. Local navigation of mobile robot is always in associate with the sensors to give signal about object detection on the outer environment in order to locate itself in that environment and to generate a map of the corresponding environment.

A common mobile robot utilizes infrared, laser, or ultrasonic sensors for collecting data for its path planning [7-9]. However, this type of sensors only gives data in an imperceptible way. The algorithm involves mathematical computation of the input data perceives from the time of receiving light radiation or sound signal transmitted from a source mounted on the robot. The sensor system sometimes could be inaccurate due 
to interruption of the traveling signal caused by disturbance from the surroundings environment which will result in incorrect data reception [10].

Therefore, a vision sensor is an alternative to replace the ordinary sensors applied in mobile robot. The image captured by camera is a visualizing data which will be perceived by the processing unit and analyzed with algorithms to interpret it into usable information for path planning of the robot.

A monocular vision system consists of one camera as the input sensor. The implementation of monocular vision system on mobile robot would require the pre-calibration of the camera with the aid of a calibration object consists of similarity in certain features such as color or shape with the object to be detected [11-12]. In order to integrate the vision system with the robot motion system, programming is a must to create algorithms for computing the value of motion parameters corresponding to the data like pixel coordinates obtained from the input image. Path planning will be decided regarding to the information extracted from the interpreted data. The motion parameter values are required to send a signal command to the actuators of the robot for its corresponding movement to achieve the goal.

The vision-guided navigation system can provide greater accuracy and precision system for the mobile robot to do its tasks. The monocular vision system mobile robot is ideally to be applied in an indoor environment. Additionally, obstacle avoidance feature of the mobile robot is very useful for multiple applications such as path-following and material handling especially for dynamic environment [13-14]. In this research project, path following and static obstacle avoidance would be the function of the navigation system implies at. Thus, the capability to avoid obstacle without collision and navigate through the indoor environment within a short period are the aims to be achieved by the navigation system.

This study aims to investigate the navigation requirements of a mobile robot. Consequently, a number of articles have been surveyed especially those related to vision-based navigation system for mobile robot. With regards to the research areas of robot navigation as shown in Figure 1, this study focuses on the vision-based positioning function of the robot.

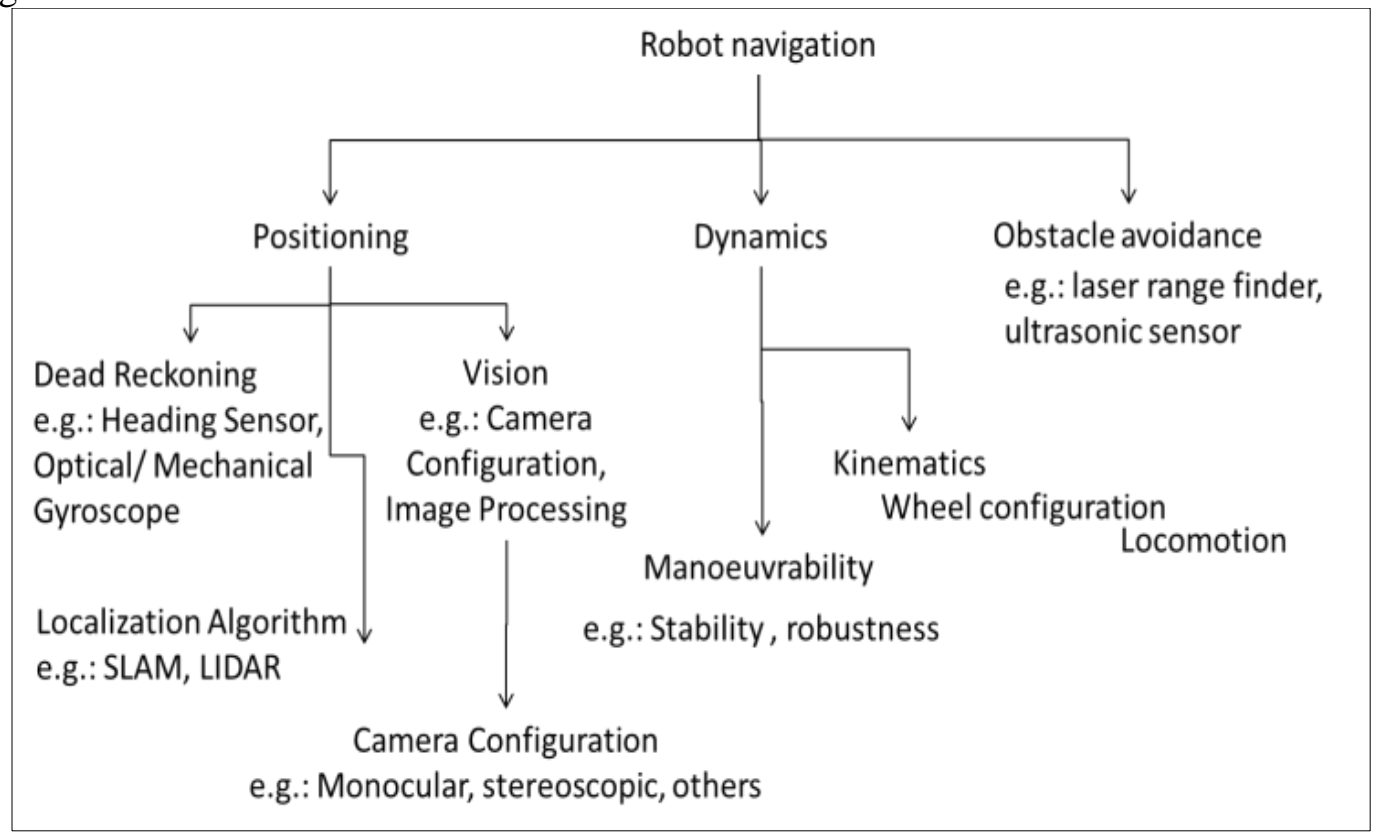

Figure 1. Research areas for Robot Navigation.

\section{Intelligence Algorithms for Vision-Based Navigation}

Vision system is the technology that helps a machine to see their environments as human sees and interpret the information to be useful information to later be used for specific purposes. Review on the obstacle detection techniques for outdoor environment has also been conducted by Singh and Kaur [15].

Crisman and Thorpe [16] claimed that the navigation system of a mobile robot comprises of perception systems to detect surroundings, path planning systems to arrange the route, and motor control systems to 
activate the movement of the robot body. For road navigation, no less than one recognition system has to detect the area of paths.

Moreover, previous research also shows that vision strategies are exceptionally compelling base in the shut extent navigation. Basically, the main consideration in utilizing image sensors and processing is its influence to the exactness of the navigation system [17]. For navigating purpose, a mobile robot needs to translate its sensing information into concentrate surroundings data so that its location can be identified. Then, the robot must choose the proper way to accomplish its goal. After that, the driving system of the mobile robot will be activated to reach its destination.

Their research vision system has the purpose to recognize circle as a landmark and determine distance and orientation from the target image for short-ranged navigation. The system is more adaptable in an indoor environment for local navigation via feature (circle) pursuing algorithm using fuzzy logic to generate target trajectory of the moving robot as depicted in Figure 2.

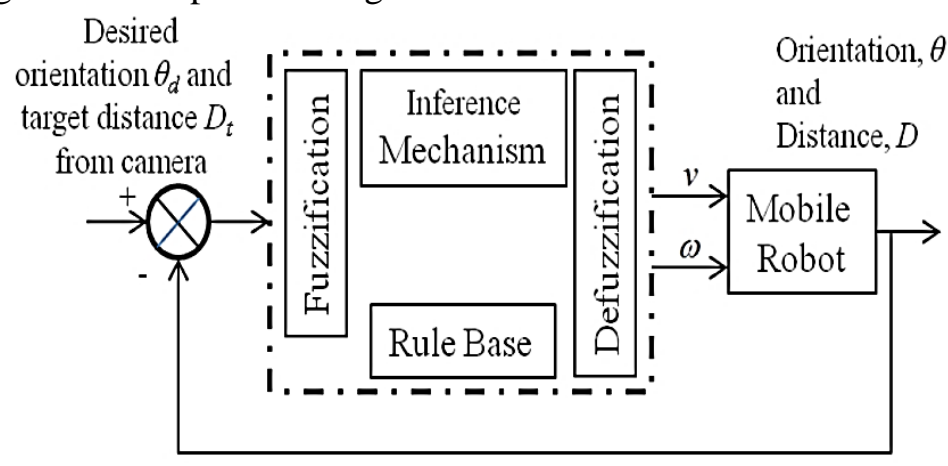

Figure 2. A cascade control system for target trajectory [17]

Giuseppina and Alberto [18] proved that a single camera can take care of issues within an indoor environment with a modestly alterable framework as the mobile robot proceeds onward horizontal surface. The single camera vision is capable to navigate mobile robot on an indoor floor while avoiding obstacle and people by using a little prior information, on-board calculation, and without omnidirectional vision.

The rest of the tasks are: map learning; route decision making and avoidance of collision with an obstacle; and self-localization. The learning of map is a very much contemplated region, yet build of map utilizing monocular vision would give many benefits compared to other sensors that are higher reliable but higher cost either such as laser rangefinder. The ground image data can be changed into grip map, which consists of certain value to determine whether there is an obstacle on the floor.

\section{Vision-based Technology for Mobile Robot}

In developing a complete mobile robot based on Simultaneous Localization and Mapping (SLAM) featurebased program, a generic system hierarchy that can be applied to develop mobile robot navigation has been proposed [19]. The hierarchy is illustrated in Figure 3. 


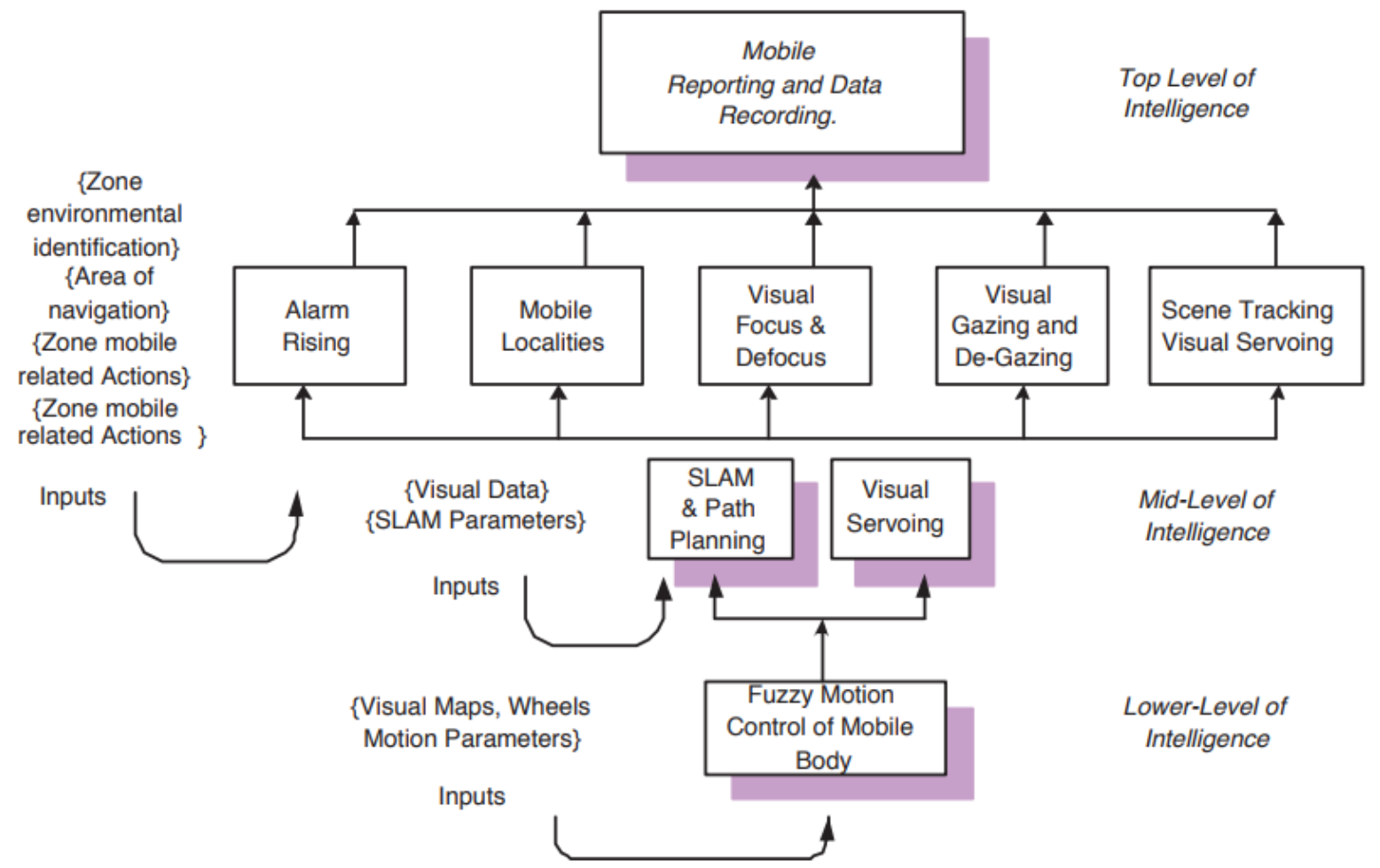

Figure 3. Mobile navigation hierarchy [19].

\subsection{Monocular Vision}

In various techniques and methods being used for positioning, the common problems are to determine the vehicle's orientation as well as its positioning. As discussed earlier, the technique used in landmark-based positioning and map-based positioning is being used for vision based positioning. Vision based positioning utilizes optical sensor instead of using another sensor. Examples of optical sensor commonly being used are such laser-based range finders and photometric cameras which use CCD arrays [20]. Using visual sensor gives user a very large amount of information regarding a mobile robot's surroundings. Plus, visual sensor could be the best source of information compared to any other sensor being introduced up to this day. Due to visual sensor's ability to offer user a tremendous value of information, the extraction of the features being observed in relation to obtain positioning information is not a simple task. The problems of localization by using the vision based technique have attracted a lot of attentions of researches and thus several techniques to overcome the problems have been proposed. Several techniques that can be identified are such:

- $\quad$ Environment representations;

- $\quad$ Algorithm for image localization;

- $\quad$ Procedure of sensing.

Typically, absolute or relative position data can be obtained by using most localization techniques. Different techniques give out different results and information depending on the type of sensor being utilized, the geometric models as well as the representation of the environment [21]. Additionally, other geometric data of the surroundings can be provided in many forms such as landmarks, the shape of an item, or a map of the environment in either 2-dimensional or 3-dimensional map. This is illustrated in Figure 4. A vision sensor or in some cases where multiple vision sensors are implemented, it is expected to recognizes an image features or area on an image and compares the image with the image or maps being stored in the memory. 


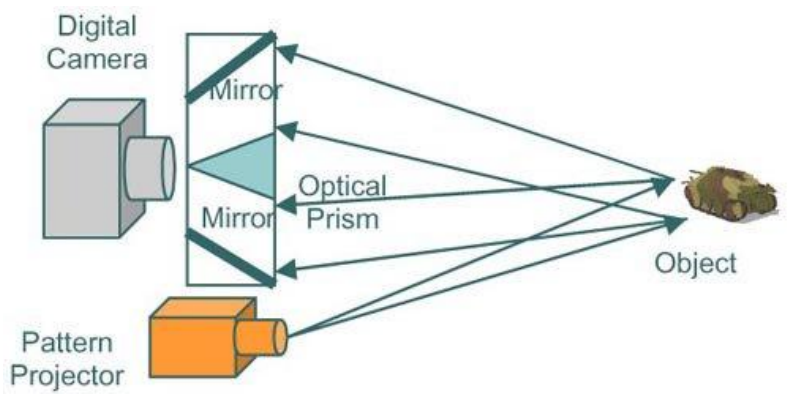

Figure 4. Monocular vision system [21]

In addition, landmarks, object models, and maps should be able to give out good information that could easily be detected or identified. In a wider sense, "positioning" in mobile robots also gives a meaning to find position as well as the orientation of a mobile robot or a sensor.

The first type which is a monocular vision system with only single camera mounted on the robot to grab the image of its surroundings. The camera must be pre-calibrated so that feature information can be acquired from the image captured by the single camera. Edge detection and color detection are examples of method used in monocular vision system to distinguish objects or obstacles in the image.

Monocular vision system needed to move into two different points to obtain single 3-dimensional information of the object [22]. It is also possible to configure multiple cameras in monocular vision configuration. In that case, the field of view in the eyes are commonly do not overlap or may overlap only a little with each other. Monocular vision does not develop and gives an information for 3-dimensional. Monocular vision also could not give an exact value of position and distance.

Additionally, a monocular vision can be easily disturbed and gives wrong interpretation and calculation of the vision. In all the advantages, there is a higher difficulty in implementing vision system due to the demand of perfect accuracy of the alignment of the cameras which requires expert technique or high precision machine that may lead to very high cost [23].

\subsection{Stereo Vision System}

Apart from monocular vision system, there is stereo vision system that comprises of two identical cameras installed on the robot for image capturing as shown in Figure 5 [24].

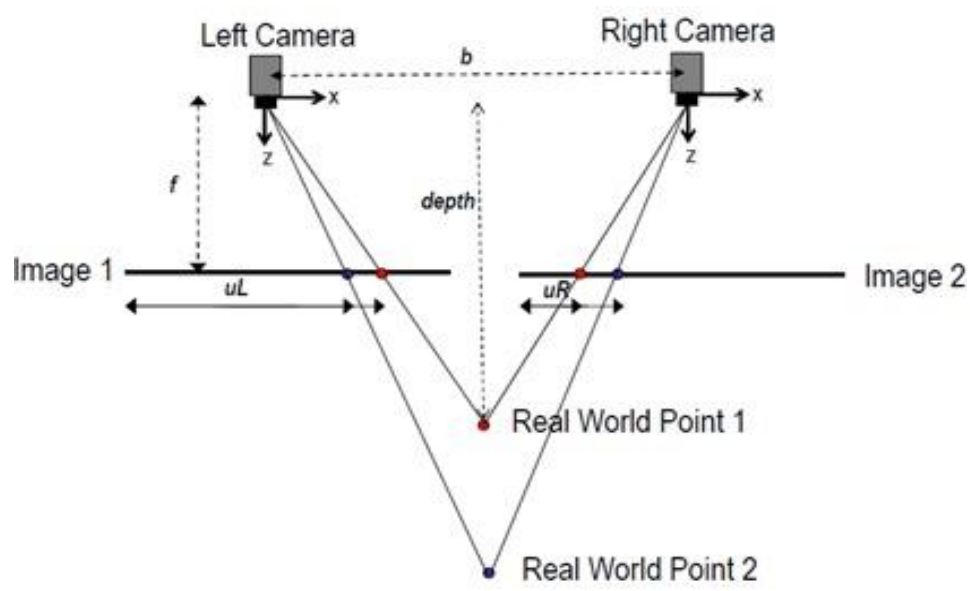

Figure 5. Stereo vision system [24]

This type of vision system is way more capable of predicting the distance of the object just like the stereo vision possessed by human being and most of the predatory animals of their natural ability. By the way, there is a higher difficulty in implementing this stereo vision system due to the perfectly demand of accuracy for the alignment of the cameras which requires expertise technique or high precision machine that may cause to very high cost. 
As an instance, Carnegie Robotics developed a sensing device that combine tri-modal of laser, 3D stereo, and video. The device that is known as MultiSense SL could act like a head for humanoid or mobile robot [25]. The MultiSense SL is illustrated in Figure 6.

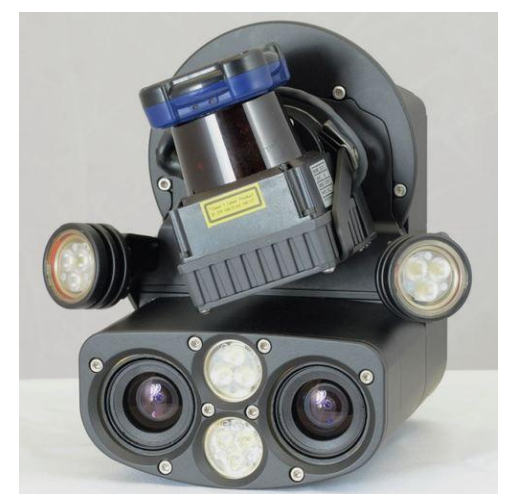

Figure 6. Stereo vision system [25]

\subsection{Other Vision System}

Another type of robot vision is the trinocular vision. Figure 7 illustrates the concept of the vision system. The system is particularly useful when the robot needs to consider wider scope of view as depicted in Figure 8. On the other hand, some researches also utilized the third camera to verify certain information captured by stereo camera. Fig. 9 illustrates an example of a trinocular robot vision.

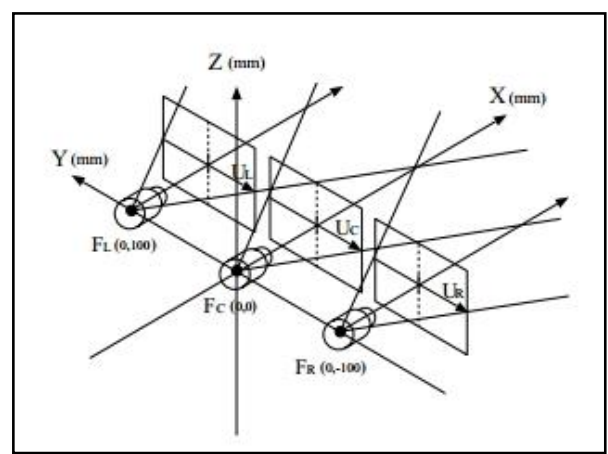

Figure 7. Concept of a trinocular vision system [22]

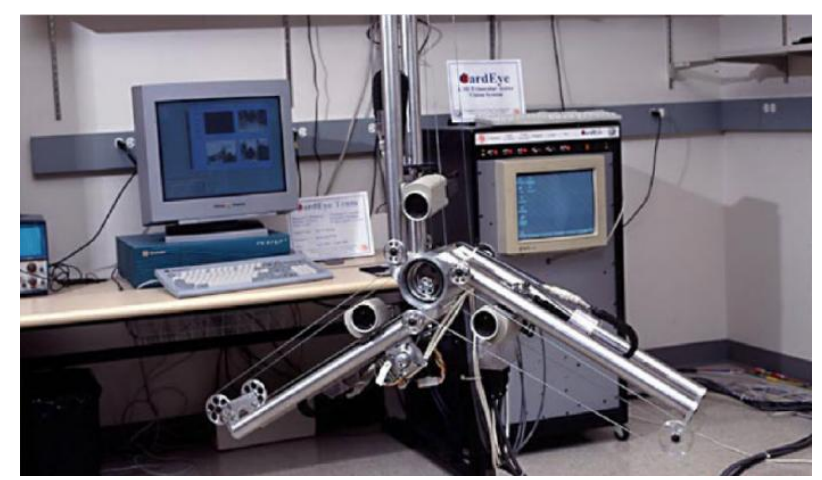

Figure 8. Trinocular vision system [26]

\section{Recent Development of Intelligent Vision-Based Mobile Robot Navigation Systems}

There is numerous vision systems developed for the navigation of mobile robot. The advancement of computing technology has also enabled researchers to develop more efficient and reliable navigation system. 
The researches could be categorized into three vision categories: monocular, stereo and trinocular visions. The details for related researches conducted are summarized in Table 1, Table 2 and Table 3 respectively.

Table 1. Related Researches on Monocular Vision System for Mobile Robot Navigation.

\begin{tabular}{|c|c|c|c|}
\hline Authors & Contributions & $\begin{array}{l}\text { Intelligent navigation } \\
\text { strategy/ algorithm }\end{array}$ & $\begin{array}{l}\text { Vision } \\
\text { Type }\end{array}$ \\
\hline $\begin{array}{l}\text { Eric } \\
\text { Royer et } \\
\text { al. [27] }\end{array}$ & $\begin{array}{l}\text { Equip motion algorithm } \\
\text { with capability to build a } \\
\text { 3D map from its learning } \\
\text { sequence }\end{array}$ & $\begin{array}{c}\text { Map building and localization } \\
\text { algorithm based on the data } \\
\text { collected by single front } \\
\text { camera }\end{array}$ & Monocular \\
\hline $\begin{array}{l}\text { Dörfle } \\
\text { et al. } \\
\text { [28] }\end{array}$ & $\begin{array}{c}\text { Develop position } \\
\text { recognition method based } \\
\text { on angle differences }\end{array}$ & $\begin{array}{c}\text { Monocular localization and } \\
\text { navigation with obstacle } \\
\text { avoidance function }\end{array}$ & Monocular \\
\hline $\begin{array}{l}\text { Forster } \\
\text { et al. } \\
\text { [29] }\end{array}$ & $\begin{array}{l}\text { Develop a faster visual } \\
\text { odometry algorithm }\end{array}$ & $\begin{array}{l}\text { Intelligent motion estimation } \\
\text { algorithm that eliminates the } \\
\text { required feature extraction } \\
\text { and robust matching } \\
\text { techniques }\end{array}$ & Monocular \\
\hline $\begin{array}{l}\text { Sujiwo } \\
\text { et al. } \\
{[30]}\end{array}$ & $\begin{array}{c}\text { Develop higher accuracy } \\
\text { localization }\end{array}$ & $\begin{array}{c}\text { Combined mapping algorithm } \\
\text { based on Velodyne LIDAR } \\
\text { SLAM and ORB-SLAM } \\
\text { methods }\end{array}$ & Monocular \\
\hline $\begin{array}{c}\text { Ishida et } \\
\text { al. [31] }\end{array}$ & $\begin{array}{l}\text { Combined the utilization of } \\
\text { CMOS camera and sensors } \\
\text { (gas and airflow) to search } \\
\text { for the possible gas-leaking } \\
\text { source }\end{array}$ & $\begin{array}{c}\text { Behavior-based architecture } \\
\text { that is capable to respond } \\
\text { dynamically }\end{array}$ & Monocular \\
\hline $\begin{array}{l}\text { Básaca- } \\
\text { Preciado } \\
\text { et al. } \\
\text { [32] }\end{array}$ & $\begin{array}{l}\text { Develop an obstacle } \\
\text { avoidance function in an } \\
\text { unknown } \\
\text { environment using optical } \\
\text { 3D laser measurement } \\
\text { system }\end{array}$ & $\begin{array}{c}\text { Produce localization scheme } \\
\text { by dynamic triangulation by } \\
\text { combining } 3 \mathrm{D} \text { laser and } \\
\text { camera visions }\end{array}$ & $\begin{array}{l}\text { Optical } \\
\text { 3D Laser } \\
\text { and } \\
\text { camera } \\
\text { vision }\end{array}$ \\
\hline $\begin{array}{l}\text { Siagian } \\
\text { et al. } \\
\text { [33] }\end{array}$ & $\begin{array}{l}\text { Combine topological and } \\
\text { grid-occupancy maps to } \\
\text { integrate the outputs from } \\
\text { all modules }\end{array}$ & $\begin{array}{l}\text { Combination of fast and slow } \\
\text { modules to obtain acceptable } \\
\text { solutions within time }\end{array}$ & $\begin{array}{l}\text { Monocular } \\
\text { and laser } \\
\text { range } \\
\text { finder }\end{array}$ \\
\hline $\begin{array}{l}\text { Guzel } \\
\text { and } \\
\text { Bicker } \\
{[34]}\end{array}$ & $\begin{array}{l}\text { Develop behaviour-based } \\
\text { architecture for mapless } \\
\text { robot navigation }\end{array}$ & $\begin{array}{l}\text { Modular design of navigation } \\
\text { behaviour with neural } \\
\text { network-based algorithm for } \\
\text { obstacle avoidance purpose }\end{array}$ & $\begin{array}{l}\text { Monocular } \\
\text { vision }\end{array}$ \\
\hline $\begin{array}{l}\text { Tsai et } \\
\text { al. [35] }\end{array}$ & $\begin{array}{l}\text { The main goal is to detect } \\
\text { and avoid obstacles in the } \\
\text { outdoor environment }\end{array}$ & $\begin{array}{l}\text { Adopted a dense optical flow } \\
\text { method to extract data for a } \\
\text { classifier model using support } \\
\text { vector machine (SVM). }\end{array}$ & $\begin{array}{l}\text { Monocular } \\
\text { vision }\end{array}$ \\
\hline $\begin{array}{l}\text { Jia et al. } \\
{[36]}\end{array}$ & $\begin{array}{l}\text { Propose an obstacle } \\
\text { avoidance mechanism for } \\
\text { driver-assistance systems }\end{array}$ & $\begin{array}{l}\text { Adopted a dense optical flow } \\
\text { method to extract data for a } \\
\text { classifier model using support } \\
\text { vector machine (SVM). }\end{array}$ & $\begin{array}{l}\text { Monocular } \\
\text { vision }\end{array}$ \\
\hline
\end{tabular}




\begin{tabular}{|c|c|c|c|}
\hline $\begin{array}{l}\text { Keivan } \\
\text { and } \\
\text { Sibley } \\
\text { [37] }\end{array}$ & $\begin{array}{c}\text { Develop a visual-inertial } \\
\text { simultaneous localization } \\
\text { and mapping (SLAM) based } \\
\text { on nonlinear-optimization } \\
\text { approach }\end{array}$ & $\begin{array}{l}\text { Optimizing visual map that } \\
\text { incorporate relocation and } \\
\text { close loop constraint }\end{array}$ & Monocular \\
\hline
\end{tabular}

Table 2. Related Researches on Stereo Vision System for Mobile Robot Navigation.

\begin{tabular}{|c|c|c|c|}
\hline $\begin{array}{c}\text { Murray } \\
\text { and Little } \\
\text { [38] }\end{array}$ & $\begin{array}{c}\text { Developed a method that } \\
\text { reduces the disparity images } \\
\text { obtained from stereo vision to } \\
\text { two-dimensional information }\end{array}$ & $\begin{array}{c}\text { Disparity image } \\
\text { segmentation to eliminate } \\
\text { stereo mismatches }\end{array}$ & $\begin{array}{c}\text { Stereo } \\
\text { vision }\end{array}$ \\
\hline $\begin{array}{c}\text { Kao et al. } \\
\text { [39] }\end{array}$ & $\begin{array}{c}\text { Integrate multi-camera vision } \\
\text { systems to catch a flying ball }\end{array}$ & $\begin{array}{c}\text { Trajectory planning } \\
\text { based on feedback } \\
\text { linearization and } \\
\text { proportional-integral- } \\
\text { derivative (PID) control }\end{array}$ & $\begin{array}{c}\text { Active } \\
\text { stereo } \\
\text { vision and } \\
\text { static } \\
\text { camera }\end{array}$ \\
\hline $\begin{array}{c}\text { Salmerón- } \\
\text { Garc1'a et } \\
\text { al. [40] }\end{array}$ & $\begin{array}{c}\text { Develop a hierarchical cloud- } \\
\text { based architecture for robot } \\
\text { navigation }\end{array}$ & $\begin{array}{c}\text { Offloading computation } \\
\text { to the Cloud with } \\
\text { Openstack Havana as the } \\
\text { cloud middleware }\end{array}$ & $\begin{array}{c}\text { Stereo } \\
\text { vision }\end{array}$ \\
\hline $\begin{array}{c}\text { Al-Mutib } \\
\text { et al. [19] }\end{array}$ & $\begin{array}{c}\text { Proposed a Mobile navigation } \\
\text { hierarchy and develop a fuzzy }\end{array}$ & $\begin{array}{c}\text { SLAM based fuzzy } \\
\text { autonomous navigation }\end{array}$ & $\begin{array}{c}\text { Stereo } \\
\text { vision }\end{array}$ \\
\hline $\begin{array}{c}\text { Ghazouani } \\
\text { et al. [41] }\end{array}$ & $\begin{array}{c}\text { Proposed function to update } \\
\text { based on credibility weightage } \\
\text { to represent the influence of } \\
\text { new observation }\end{array}$ & $\begin{array}{c}\text { Navigation map building } \\
\text { based on 3D Occupancy }\end{array}$ & $\begin{array}{c}\text { Stereo } \\
\text { vision }\end{array}$ \\
\hline $\begin{array}{c}\text { Ball et al. } \\
\text { [42] }\end{array}$ & $\begin{array}{c}\text { Proposed a hybrid system } \\
\text { consists of localized vision, } \\
\text { global positioning system and } \\
\text { inertial navigation system }\end{array}$ & $\begin{array}{c}\text { Generate feasible robot } \\
\text { path based on combined } \\
\text { obstacle detection and } \\
\text { visually-aided guidance. }\end{array}$ & $\begin{array}{c}\text { Stereo } \\
\text { vision }\end{array}$ \\
\hline $\begin{array}{c}\text { Cheng } \\
\text { al. [43] }\end{array}$ & $\begin{array}{c}\text { Propose an asynchronous } \\
\text { Kalman filter to fuse the data } \\
\text { from fuzzy maps. }\end{array}$ & $\begin{array}{l}\text { Capability } \\
\text { intermittent } \\
\text { for robot localization. } \\
\text { correction }\end{array}$ & $\begin{array}{c}\text { Stereo } \\
\text { vision }\end{array}$ \\
\hline
\end{tabular}

Table 3. Related Researches on Trinocular Vision System for Mobile Robot Navigation.

\begin{tabular}{|c|c|c|l|}
\hline $\begin{array}{c}\text { Min and } \\
\text { Cho [44] }\end{array}$ & $\begin{array}{c}\text { Active trinocular vision } \\
\text { system with capability to } \\
\text { extract 3D information } \\
\text { from single shot image }\end{array}$ & $\begin{array}{c}\text { Utilize probabilistic voting and } \\
\text { line grouping data as input for } \\
\text { intelligent matching algorithms }\end{array}$ & Trinocular \\
\hline $\begin{array}{c}\text { Lu and } \\
\text { Shao } \\
{[45]}\end{array}$ & $\begin{array}{c}\text { New method that focuses } \\
\text { on the calibration of the } \\
\text { trinocular vision sensor. }\end{array}$ & $\begin{array}{c}\text { Proposed a sphere-based } \\
\text { transformation procedure } \\
\text { based on trifocal tensor } \\
\text { approach }\end{array}$ & Trinocular \\
\hline $\begin{array}{c}\text { Hemayed } \\
{[26]}\end{array}$ & $\begin{array}{c}\text { Develop and } \\
\text { commercialize a modular } \\
\text { vision system for } \\
\text { humanoid / mobile robot. }\end{array}$ & $\begin{array}{c}\text { Algorithm for multi-stage } \\
\text { surface reconstruction based } \\
\text { on depth information }\end{array}$ & Trinocular \\
& \multicolumn{2}{|c}{} & \\
\hline
\end{tabular}




\begin{tabular}{|c|c|c|c|}
\hline $\begin{array}{c}\text { Liu et al. } \\
{[46]}\end{array}$ & $\begin{array}{c}\text { Proposed a master control } \\
\text { system based on trinocular } \\
\text { configuration of camera. }\end{array}$ & $\begin{array}{c}\text { Kalman filter for prediction of } \\
\text { speed and direction of the } \\
\text { master handle's next position }\end{array}$ & Trinocular \\
\hline $\begin{array}{c}\text { Liu et al. } \\
\text { [47] }\end{array}$ & $\begin{array}{c}\text { Proposed an intelligent } \\
\text { picking movement for } \\
\text { robot arm based on } \\
\text { trinocular vision. }\end{array}$ & $\begin{array}{c}\text { Adaptive and fuzzy image } \\
\text { fusion to increase robot's } \\
\text { picking ability }\end{array}$ & Trinocular \\
\hline
\end{tabular}

\section{Conclusions}

The advancement of computing technology has enabled researchers to develop vision system with higher capability. This contributes towards the improvement of navigation system for mobile robots. However, most of the researches still opted for having monocular vision system instead of stereo or trinocular vision configurations. This is to minimize the computation requirement hence increase the efficiency

\section{Acknowledgements}

The authors wish to thank Universiti Teknikal Malaysia Melaka, Silterra Malaysia Sdn. Bhd and Fundamental Research Grant Scheme (FRGS) for financially support this work.

\section{References}

[1] S. Ekiz, "Solving Constrained Optimization Problems with Sine-Cosine Algorithm," Periodicals of Engineering and Natural Sciences, vol. 5 no. 3, pp. 378-386, 2017

[2] B. Durakovic,. "Design of Experiments Application, Concepts, Examples: State of the Art," Periodicals of Engineering and Natural Sciences, vol. 5 no. 3, pp. 421-439, 2017.

[3] O. Gursoy and M.H.Sharif, "Parallel Computing for Artificial Neural Network Training," Periodicals of Engineering and Natural Sciences, vol. 6 no. 1, pp.1-10, 2018.

[4] A.Z. Mohamed Noor, M.H.F. Md Fauadi, F.A. Jafar, M.H. Nordin, S.H. Yahaya, S. Ramlan, M.A. Shri Abdul Aziz, "Fuzzy Analytic Hierarchy Process (FAHP) Integrations for Decision Making Purposes: A Review," Journal of Advanced Manufacturing Technology, vol. 11 no. 2, pp. 139-154.

[5] M.H. Sharif, I. Despot, and S. Uyaver, "A Proof of Concept for Home Automation System with Implementation of the Internet of Things Standards," Periodicals of Engineering and Natural Sciences, vol. 6 no. 1, pp.95-106, 2018.

[6] D. R. Parhi and A.K. Jha, "Review and Analysis of Different Methodologies used in Mobile Robot," International Journal of Applied Artificial Intelligence in Engineering System, vol. 4, no. 1, pp. 1-18, 2012.

[7] N.Y. Ko and T.Y. Kuc, "Fusing Range Measurements from Ultrasonic Beacons and a Laser Range Finder for Localization of a Mobile Robot," Sensors, vol. 15 no. 5, pp. 11050-11075, 2015.

[8] T. Mohammad, "Using Ultrasonic and Infrared Sensors for Distance Measurement," International Journal of Mechanical, Aerospace, Industrial, Mechatronic and Manufacturing Engineering, vol. 3, no. 3, pp. 267-272, 2009

[9] Turkmen, Anil Can. "Autonomous Car Parking System with Various Trajectories," Periodicals of Engineering and Natural Sciences, vol. 5, no. 3, pp. 364-370, 2017.

[10] F.D. Ponte Müller, "Survey on Ranging Sensors and Cooperative Techniques for Relative Positioning of Vehicles," Sensors, vol. 17, pp.271, 2017

[11] P. Lébraly, C. Deymier, O. Ait-Aider, E. Royer and M. Dhome, "Flexible extrinsic calibration of non-overlapping cameras using a planar mirror: Application to vision-based robotics," 2010 IEEE/RSJ International Conference on Intelligent Robots and Systems, Taipei, 2010, pp. 5640-5647

[12] A.J.R. Neves, A.J. Pinho, D.A. Martins and B. Cunha, "An efficient omnidirectional vision system for soccer robots: From calibration to object detection," Mechatronics, vol. 21, no. 2, pp 399-410, 2011. 
[13] M. Faisal, R. Hedjar, M. Al Sulaiman, K. Al-Mutib, "Fuzzy Logic Navigation and Obstacle Avoidance by a Mobile Robot in an Unknown Dynamic Environment," International Journal of Advanced Robotic Systems, vol. 10, no. 1, pp. 1-7, 2013

[14] J. Minguez and L. Montano, "Extending Collision Avoidance Methods to Consider the Vehicle Shape, Kinematics, and Dynamics of a Mobile Robot," IEEE Transactions on Robotics, vol. 25, no. 2, pp. 367-381, 2009.

[15] Y. Singh and L. Kaur, "Obstacle Detection Techniques in Outdoor Environment: Process, Study and Analysis," International Journal of Image, Graphics and Signal Processing, vol. 5, pp. 35-53, 2017.

[16] J. D. Crisman and C. E. Thorpe, "SCARF: a color vision system that tracks roads and intersections," IEEE Transactions on Robotics and Automation, vol. 9, no. 1, pp. 49-58, 1993.

[17] M Saifizi, D Hazry, Rudzuan M Nor, "Controlling a Mindstorms Robot using Image Processing on Android Devices," International Journal of Control Science and Engineering, vol. 2 no. 4, pp. 8387, 2012.

[18] G. Gini and A. Marchi, "Indoor Robot Navigation With Single Camera Vision", Proceedings of the 2nd International Workshop on Pattern Recognition in Information Systems (PRIS 2002), Ciudad Real, Spain, April 2002

[19] K. Al-Mutib, E. Mattar, M. Alsulaiman, "Implementation of Fuzzy Decision Based Mobile Robot Navigation Using Stereo Vision,” Procedia Computer Science, vol. 62, pp. 143-150, 2015.

[20] M. Baba and K. Ohtani, "A new sensor system for simultaneously detecting the position and incident angle of a light spot," Journal of Optics A: Pure and Applied Optics, vol . 4, no. 6, pp. s391-s399, 2002.

[21] T. Lu and C. Tien-Hsin, "A single-camera system captures high-resolution 3D images in one shot", Available: http://spie.org/newsroom/0303-a-single-camera-system-captures-high-resolution-3dimages-in-one-shot?SSO=1

[22] A. Ohya, Y. Miyazaki, and S. I. Yuta, "Autonomous navigation of mobile robot based on teaching and playback using trinocular vision," Industrial Electronics Society, 2001 (IECON'01), The 27th Annual Conference of the IEEE (Vol. 1, pp. 398-403), 2001.

[23] S. Lecorné and A. Weitzenfeld, "Robot navigation using stereo-vision", Retrieved from: http://weitzenfeld.robolat.org/wp-content/uploads/2015/01/OpticFlow.pdf

[24] National Instruments. "3D Imaging with NI LabVIEW," Jan 04, 2017. Available: http://www.ni.com/white-paper/14103/en/

[25] Carnegie Robotics LLC, “MultiSense SL”, Retrieved: http://carnegierobotics.com/multisense-sl/

[26] E.E. Hemayed, "A 3D trinocular active vision system for surface reconstruction”, Ph.D Thesis, University of Louiseville, 1999

[27] E. Royer, M. Lhuillier, M. Dhome, et al., "Monocular Vision for Mobile Robot Localization and Autonomous Navigation", International Journal of Computer Vision, vol. 74, no. 3, pp 237-260, 2007.

[28] M. Dörfle, L. Přeučil, M. Kulich, "Vision-Based Pose Recognition, Application for Monocular Robot Navigation", Second Iberian Robotics Conference on Robot, 2015: pp 451-463

[29] C. Forster, M. Pizzoli and D. Scaramuzza, "SVO: Fast semi-direct monocular visual odometry", 2014 IEEE International Conference on Robotics and Automation (ICRA), Hong Kong, 2014, pp. $15-22$.

[30] A. Sujiwo, T. Ando, E. Takeuchi, Y. Ninomiya, and M. Edahiro, "Monocular Vision-Based Localization Using ORB-SLAM with LIDAR-Aided Mapping in Real-World Robot Challenge", Journal of Robotics and Mechatronics, vol. 28 no.4, pp. 479-490, 2016.

[31] H. Ishida, H. Tanaka, H. Taniguchi, T. Moriizumi, "Mobile robot navigation using vision and olfaction to search for a gas/odor source", Autonomous Robots, vol. 20, no. 3, pp 231-238, 2006. 
[32] L.C. Básaca-Preciado, O.Y. Yu. Sergiyenko, J. C. Rodríguez-Quinonez et al, "Optical 3D laser measurement system for navigation of autonomous mobile robot", Optics and Lasers in Engineering, vol. 54, pp. 159-169, 2014.

[33] C. Siagian, C.K. Chang, L. Itti, "Autonomous Mobile Robot Localization and Navigation Using a Hierarchical Map Representation Primarily Guided by Vision", Journal of Field Robotics, vol. 31, no. 3, pp. 408-440, 2014.

[34] M.S. Guzel, R. Bicker, "A Behaviour-Based Architecture for Mapless Navigation Using Vision", International Journal of Advanced Robotic Systems, vol. 9, no. 1, pp. 1-13, 2012.

[35] C.C. Tsai, C.W. Chang, C.W. Tao, "Vision-Based Obstacle Detection for Mobile Robot in Outdoor Environment," Journal of Information Science \& Engineering, vol. 34, no. 1, pp. 21-34, 2018.

[36] B. Jia, R. Liu and M. Zhu, "Real-time obstacle detection with motion features using monocular vision," The Visual Computer, vol. 31, pp. 281-293, 2015.

[37] N. Keivan and G. Sibley, "Asynchronous adaptive conditioning for visual-inertial SLAM," The International Journal of Robotics Research, vol. 34, no. 13, pp.1573-1589, 2015.

[38] D. Murray and J.J. Little, "Using Real-Time Stereo Vision for Mobile Robot Navigation", Autonomous Robots, vol. 8, no. 2, pp 161-171, 2000.

[39] S. T. Kao, Y. Wang and M. T. Ho, "Ball catching with omni-directional wheeled mobile robot and active stereo vision", 2017 IEEE 26th International Symposium on Industrial Electronics (ISIE), Edinburgh, United Kingdom, 2017, pp. 1073-1080.

[40] J. Salmerón-Garc1'a, P. Íñigo-Blasco, F. D1'az-del-R1'o and D. Cagigas-Muñiz, "A Tradeoff Analysis of a Cloud-Based Robot Navigation Assistant Using Stereo Image Processing”, IEEE Transactions on Automation Science and Engineering, vol. 12, no. 2, pp. 444-454, 2015.

[41] H. Ghazouani, M. Tagina, R. Zapata, "Robot Navigation Map Building Using Stereo Vision Based 3D Occupancy Grid", Journal of Artificial Intelligence: Theory and Application (JAITA), vol. 1, no. 3, pp. 63-72, 2011.

[42] D. Ball, B. Upcroft, G. Wyeth, P. Corke, A. English, "Vision-based Obstacle Detection and Navigation for an Agricultural Robot", Journal of field robotics, vol. 33, no. 8, pp. 1107-1130, 2016.

[43] L. Cheng, Y. Dai, R. Peng, and X. Nong, "Positioning and navigation of mobile robot with asynchronous fusion of binocular vision system and inertial navigation system," International Journal of Advanced Robotic Systems, vol. 14, no. 6, pp. 1-16, 2017.

[44] Y. K. Min, H. S. Cho, "An active trinocular vision system of sensing indoor navigation environment for mobile robots", Sensors and Actuators A: Physical, vol. 125, no. 2, pp. 192-209, 2006.

[45] R. Lu and M. Shao, "Sphere-based calibration method for trinocular vision sensor", Optics and Lasers in Engineering, vol. 90, pp. 119-127, 2017.

[46] Q. Liu, L. Cao, J. Chen and Z. He, "The Master Manipulator Control System in a Master-Slave Robot based on Trinocular Stereo Vision", Applied Mathematics \& Information Sciences, vol. 9, no. 2, pp.749-757, 2015.

[47] C. Liu , S. Dong, B. Lu, A. Hauptmann, C. Li, "Study on Adaptive and Fuzzy Weighted Image Fusion Based on Wavelet Transform in Trinocular Vision of Picking Robot", Journal of Information \& Computational Science, vol. 11 no.7, pp. 1-9, 2014. 